\title{
Diseño y evaluación de un sistema inmunoenzimático rápido de tercera generación para la detección de anticuerpos antiVIH
}

\author{
Burgos J.D.
}

\begin{abstract}
Resumen
Una mezcla de péptidos sintéticos correspondientes a regiones conservadas e inmunodominantes de las proteínas gp41 y p24 del virus de inmunodeficiencia humana tipo 1 (VIH 1) y de p36 del VIH tipo 2, se emplearon como antígenos para el desarrollo de un sistema de microelisa para la detección de anticuerpos específicos antiVIH en suero de pacientes infectados. Este abordaje multiepitópico permite la elaboración de un ELISA rápido (20 minutos) con una sensibilidad del $99 \%$ y una especificidad del $100 \%$ cuando se enfrenta con un panel de 300 sueros: 100 de pacientes seropositivos y pacientes con SIDA y 200 muestras de donantes sanos. Estos resultados sugieren que el sistema de microelisa rápido posee una sensibilidad y especificidad comparables a la de los estuches comerciales de tercera generación disponibles actualmente.
\end{abstract}

\section{Summary}

This paper describes the development of a third generation method for the detection of specific antibodies against the Human Immunodeficiency Virus (VIH) types 1 and 2. The method uses a Microelisa, based on the use of a mixture of synthetic peptides as antigens derived from gp41 and p24 of HIV 1 and p36 of HIV 2. This system requires a total of twenty minutes (20') in order to obtain a result with $100 \%$ specificity and $99 \%$ sensitivity, comparable to the new third - generation commercially available systems.

Desde la identificación del virus de la inmunodeficiencia humana $(\mathrm{VIH})$ como el agente infeccioso causante del SIDA $(1,2)$ se han hecho grandes avances en el desarrollo de métodos diagnósticos para la detección de la infección por VIH.

Los métodos serológicos son los más usuales para la detección de individuos infectados por VIH $(3,4)$ sin embargo, se han implementado métodos tales como cultivos celulares in vitro, uso de sondas de ADN específicas y amplificación genética, para el aislamiento y detección del virus de la inmunodeficiencia humana (5); pero estos procedimientos sólo se llevan a cabo en centros especializados que cuentan con personal

Director de Investigación y Desarrollo, Alpha Diagnostics National Research. muy calificado y laboratorios sofisticados, lo cual hace que dichas técnicas se hagan a costos muy elevados.

Así, los métodos serológicos continúan siendo una herramienta esencial para la detección de sangre o de productos sanguíneos contaminados (6).

Los primeros sistemas comerciales para la detección de anticuerpos antiVIH fueron estuches deELISA (EnzymeLinkedImmunosorbentAssay), y hasta el presente, la técnica de ELISA es la más fecuentemente utilizada para detectar anticuerpos antiVIH específicos. Continuas modificaciones a estos estuches se han hecho desde la salida al mercado del primero en 1985 y su sensibilidad y especificidad se ha mejorado sustancialmente. 
Muchos de los estuches empleados alrededor del mundo para pruebas de tamizaje para infección por VIH, son aquéllos conocidos como de primera generación, los cuales se elaboran cubriendo placas para microelisa o esferas de poliestireno con lisados purificados de VIH aislado a partir de cultivos celulares, de acuerdo a los métodos establecidos porPopovic etal.(7). Recientemente, los estuches para ELISA han empezado a elaborarse empleando proteínas como antígenos, bien sea aisladas mediante columnas de afinidad o proteínas recombinantes del VIH, las cuales se conocen como sistemas de segunda generación.

Actualmente se están imponiendo, debido a su mayor sensibilidad y especificidad, los sistemas basados en el uso de péptidos, bien sea sintéticos o recombinantes, conocidos como estuches de tercera generación.

Así, la generación y desarrollo de nuevas tecnologías lleva a la creación de sistemas diagnósticos más rápidos, simples y seguros para la detección de la infección por el VIH, lo cual implica que se hagan diagnósticos cada vez más seguros y exactos (8-12). El microelisa rápido que aquí se describe corresponde a un sistema de tercera generación, que posee una elevada sensibilidad y especificidad, $99 \%$ y $100 \%$ respectivamente, además de un protocolo sencillo y rápido, siendo éste el primero de su género desarrollado en el país.

\section{Materiales y métodos}

\section{Antígenos sintéticos}

Para la detección de anticuerpos antiVIH por microelisa indirecta, se emplearon péptidos sintéticos miméticos como antígenos. Estos se elaboraron a partir de las secuencias inmunodominantes conservadas de las proteínas Gp41 y p24 del virus de inmunodeficiencia humana tipo 1 y p36 del VIH tipo $2(12,13)$, empleando el método inicialmente desarrollado por Merrifield (14). Los péptidos seleccionados (P1, P2 y P3) se escogieron con base en el cálculo de hidrofobicidad y en que ellos representan secuencias altamente conservadas entre diversas cepas de $\mathrm{VIH}$ (15). Las secuencias originales de P1, P2 y P3 se muestran en la tabla 1.
Tabla 1. Secuencias originales correspondientes a regiones inmunodominantes conservadas de $\mathrm{VIH}$ tipos 1 y 2.

\begin{tabular}{|c|c|c|c|c|}
\hline Virus & Proteína & Gen & Secuencias & Péptidos \\
\hline VIH 1 & Gp41 & env & $\begin{array}{l}\text { Leu.Gly. Leu.Trp.Gly.Lys. } \\
\text { Ser.Gly.Lys.Leu.Ile.Cys. }\end{array}$ & P1 \\
\hline VIH 1 & p24 & gag & Pro.Ser.Lys.Gly.Arg.Pro.Gly. & $\mathrm{P} 2$ \\
\hline VIH 2 & p36 & env & $\begin{array}{l}\text { Ans.Ser.Trp.Gly.Lys.Ala. } \\
\text { Phe.Arg.GIn.Val.Cys. }\end{array}$ & P3 \\
\hline
\end{tabular}

Estas secuencias están basadas en los trabajos de Wein Hobson (12). P1, P2 y P3 provienen de éstas mediante tratamientos químicos que estabilizan las estructuras secundarias y terciarias (23), las cuales mejoran sustancialmente su inmunoreactividad para ensayos en fase sólida.

Los péptidos sintéticos fueron provistos generosamente por el Laboratorio Alpha Diagnostics.

\section{Cobertura}

Las placas para microelisa (Nunc 4-69914) se cubren con una solución de carbonato y bicarbonato $\mathrm{pH} 9,6$ (17), en la cual se halla disuelta la mezcla de péptidos sintéticos a una concentración final de $1 \mu \mathrm{g}$ por foso. Se añaden $100 \mu \mathrm{l}$ por foso de la solución de péptidos y se incuba la placa a $37^{\circ} \mathrm{C}$ para asegurar la adsorción de los péptidos a la matriz de poliestireno.

\section{Pacientes y muestras}

Para este estudio se conformó un panel de 300 sueros; 100 pertenecientes a pacientes infectados por $\mathrm{VIH}$ y pacientes con SIDA, recolectados en el Laboratorio de Inmunología del Hospital de San José, y en otros centros hospitalarios y laboratorios clínicos de Santafé de Bogotá. El panel se completa con 200 sueros de donantes sanos que fueron empleados como muestras negativas. Los sueros sealicuotarony almacenaron a $-22^{\circ} \mathrm{C}$ hasta el momento de su uso.

Todas las muestran fueron corridas siempre por duplicado y numeradas por una tercera persona, de forma que durante la siembra de las muestras, no hubiera manera de distinguir los sueros positivos de los negativos.

\section{Ensayo inmunoenzimático}

Se añaden 100 microlitros $(\mu \mathrm{l})$ por foso de suero diluido (1/20) en buffer fosfato salino (PBS) $\mathrm{pH}$ 7,4 con albúmina bovina sérica (BSA) al $1 \%$; se 
incuba la placa durante 10 minutos a $37^{\circ} \mathrm{C}(18)$. Posteriormente, se efectúan cinco lavados con PBS al cual se le adiciona $0,05 \%$ de Tween 20 (PBS-T). Se añaden $100 \mu \mathrm{l}$ por foso de anti lgG humana acoplada a peroxidasa (Sigma A-8775), diluida (1/1000) en PBS-BSA y se incuba nuevamente durante 10 minutos a $37^{\circ} \mathrm{C}$. Se lava la placa otras cinco veces con PBS-T. Para el revelado de la reacción, se prepara una solución añadiendo una pastilla de o-fenilendiamina (OPD Sigma P 6912) a 5 mililitros de buffer citratofosfato $\mathrm{pH} 5,0$ con $30 \mu \mathrm{l}$ de $\mathrm{H} 202$ al $36 \%$ y de ésta se añaden $100 \mu \mathrm{l}$ por foso. La reacción se revela atemperaturaambiente por 2 minutos en oscuridad y se detiene con $50 \mu$ de H2SO42N. La lectura se lleva a cabo en un lector para microplacas (Titertek multiskan plus MK II) empleando un filtro de $492 \mathrm{~nm}$.

El punto de corte se calcula sumando al valor promedio de absorbancia de los negativos, dos desviaciones estándar.

La sensibilidad se determina a partir del número de sueros positivos para VIH del panel que resultaron positivos por el microelisa rápido y la especificidad a partir del número de sueros de donantes sanos que resultaron negativos por el mismo método (19).

\section{Resultados}

\section{Sensibilidad}

En el ensayo inicial del panel de 100 sueros de pacientes infectados por virus de inmunodeficiencia humana (VIH), 99 de ellos resultaron ser seropositivos cuando se probaron con el sistema de microelisa rápido, como se muestra en la tabla 2, siendo la sensibilidad del método del $99 \%$.

\section{Especificidad}

Ninguno de los sueros pertenecientes a donantes normales resultó seropositivo cuando fueron probados con este método, definiéndose así una especificidad del $100 \%$ para este sistema de diagnóstico rápido (tabla 2). Indicando esto que estas muestras no contienen anticuerpos tipo $\lg \mathrm{G}$ antiVIH.

\section{Reactividad}

Se encuentra una marcada diferencia entre la reactividad de los sueros positivos a VIH y los negativos, cuando los correspondientes valores de densidades ópticas son comparados (verfigura 1), a tal punto que es posible, sin ninguna dificultad, generar un resultado cualitativo por simple inspección visual.

\section{Discusión de resultados}

Los resultados demuestran que la mezcla de péptidos sintéticos $\mathrm{P} 1, \mathrm{P} 2$ y P3 empleados como antígenos en este microelisa rápido, presenta una elevada capacidad para la detección de anticuerpos específicos antiVIH, con una

Tabla 2. Sensibilidad y especificidad del microelisa de péptidos sintéticos de VIH 1 y 2 .

\begin{tabular}{lcc}
\hline Muestras & Donantes sanos & Pacientes infectados por VIH \\
\hline Negativas & 200 & 1 \\
Borderline & 0 & 0 \\
Positivas & 0 & 99 \\
\hline Sensibilidad & $99 \%$ & \\
Especificidad & $100 \%$ & \\
\hline
\end{tabular}

Densidades opticas

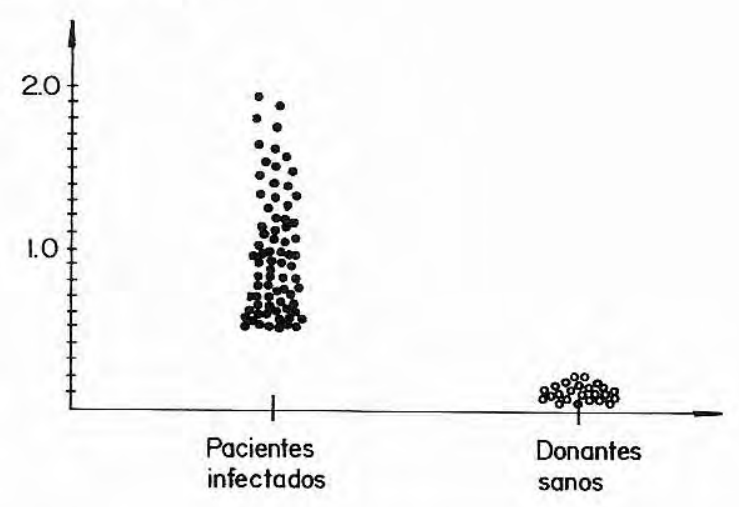

Figura 1. El promedio de lectura y densidades ópticas a 492 $\mathrm{nm}$ para los sueros normales fue de 0,125 . El punto de corte (PC) se calculó sumando a dicho promedio dos desviaciones estándar, obteniéndose así un $\mathrm{PC}=0,336$. 
sensibilidad del $99 \%$ y una especificidad del $100 \%$ cuando se encuentran con un panel de 100 sueros seropositivos y $\mathbf{2 0 0}$ de donantes normales. Este resultado puede atribuirse a los siguientes hechos: a) los péptidos corresponden a regiones inmunodominantes y conservadas; $b$ ) elevada cantidad de antígenos puros presentes en el ensayo; c) los antígenos P1, P2 y P3 están libres, dadala naturaleza de losmismos, decontaminantes inmunológicamente detectables.

Por otro lado, cabe anotar que estos altos valores de sensibilidad y especificidad se determinaron con base en el panel de sueros empleados, así que una estimación más real debe hacerse mediante un estudio de campo en el cual se cuente con un mayor número de muestras; pero estos resultados iniciales dan una indicación clara de las ventajas del método empleado, las que permiten utilizarlo no solamente como prueba primario para tamizaje de la sangre, sino además como un paso intermedio en el algoritmo de confirmación de los casos positivos. Esto permitiría disminuír el número de Western blot a realizar, descartando con este sistema de microelisa un porcentaje de los falsos positivos que hayan surgido producto del tamizaje primario que emplee otra fuente de antígenos (ej. lisados virales, proteínas recombinantes completas).

En cuanto al suero del grupo de seropositivos y de pacientes con SIDA que resultó negativo con el microelisa rápido, hay que anotar que éste pertenecía a un paciente terminal de SIDA el cual previamente había sido probado con un estuche comercial (Abbot recombinant EIA) resultando también negativo. Esto ilustra el hecho establecido de que algunos pacientes terminales de SIDA no presentan títulos de anticuerpos anti VIH detectables por ELISA o microelisa. Cabe anotar que esta muestra se tomó una semana antes de la muerte del paciente.

Ahora bien, cuando comparamos los resultados obtenidos con el microelisa rápido con los resultados de otros ensayos inmunoenzimáticos reportados, que emplean también péptidos sintéticos, encontramos que nuestrométodo rápido posee una sensibilidad y una especificidad equiparable a éstos. Gnann y colaboradores (10) empleando un péptido de 12 mer correspondiente a la región comprendida de los aminoácidos 589 a 609 de la gp 41 de HIV-1, encuentran una sensibilidad del $99,2 \%$ con un panel de 53 sueros VIH positivos y una especificidad del $100 \%$ con sueros de 30 donantes sanos. Wang y colaboradores (8), empleando un péptido sintético de gp41 -SM284- correspondiente a la región inmunodominante comprendida entre los aminoácidos 589 a 606 , determinan un $98,3 \%$ de reactividad con sueros de pacientes VIH positivos y ninguna reactividad con un panel de 118 sueros de donantes normales. Como se puede notar, la sensibilidad y especificidad de estos ensayos es muy elevada aun cuando emplean solamente péptidos sintéticos de gp 41 como antígeno, que comprenden desde el 589 hasta el 609 , región dentro de la cual está el péptido P1 de la mezcla empleada en nuestro ensayo.

Las ventajas del uso de múltiples epítopes se notan en los resultados de Thorn y colaboradores (10), quienes empleando un antígeno recombinante único, el CBre3, diseñado a partir de secuencias inmunorreactivas de las proteínas gp120 y gp41 de $\mathrm{VIH}-1$, encuentran que dicho antígeno presenta un $100 \%$ de sensibilidad y un $100 \%$ de especificidad empleando 0,25 densidades ópticas como valor mínimo para las muestras positivas, las cuales estaban clasificadas en este ensayo desde seropositivos asintomáticos hasta pacientes con SIDA en el estadio Walter Reed III. Desde este punto de vista, nuestro ensayo tendría una sensibilidad y especificidad igual al del CBre3. De ello se desprende que la aproximación más correcta es la de emplear múltiples epítopes con fines diagnósticos, dado que de esta forma se pueden detectar otros anticuerpos anti VIH que se pasan por alto cuando se emplea un solo determinante como antígeno. Esta es la razón por la cual en nuestro ensayo se emplean, además del péptido $\mathrm{P} 1$ correspondiente a un epítope de gp41 de VIH-1, otro péptido, el P2 dep24, partiendo de la base de que existe un reconocimiento temprano de esta proteína en el proceso de infección por VIH. También se agrega a la mezcla el péptido $\mathrm{P} 3$, correspondiente a una región inmunorreactiva de p36 de $\mathrm{VIH}-2$ (9), debido al avance que tiene la infección por este segundo 
virus en el mundo.

Este abordaje multiepitópico tiene una clara base biológica; los análisis de seroconversión demuestran que los individuos afectados desarrollan anticuerpos contra más proteínas del virus durante el transcurso de la infección.

De otra parte, cuando se comparan los resultados obtenidos con el microelisa rápido con los del sistema recombinante cubano, tal vez el primer estuche diagnóstico hecho en América Latina, seencuentrauna mayorespecificidad del microelisa rápido: $100 \%$ versus $98,7 \%$ del sistema recombinante cubano (20), el cual tiene las proteínas p24 y gp41 clonadas y expresadas en E. coli. Esta diferencia puede explicarse si se tiene en cuenta que cuando se obtienen los determinantes antigénicos unidos a grandes proteínas de fusión, se generan determinantes antigénicos inespecíficos lo que implica una disminución de la especificidad del método. De allí la ventaja que poseen los sistemas de tercera generación, en los cuales se emplea solamente la secuencia correspondiente al determinante o determinantes elegidos como antígenos para sensibilizar la fase sólida donde se lleva a cabo el inmunoensayo.

El microelisa que hemos desarrollado, el primero en el país, posee características que lo hacen útil tanto en laboratorios o clínicas sencillas de áreas apartadas, como en sitios especializados bien equipados, para elaborar tamizajes dentro de poblaciones tanto generales como de riesgo, así como también para la confrontación serológica en los pacientes que se sospeche infectados por VIH.

Tiene una ventaja adicional no despreciable, la rapidez; la gran mayoría de los estuches de ELISA o microelisa necesitan al menos 1 hora de incubación antes de tenerun resultado; el microelisa rápido obtiene dicho resultado en sólo veinte minutos, con una sensibilidad y especificidad mayor, debido a que emplea péptidos sintéticos acoplados a microplacas de alta afinidad, lo cual lo hace muy útil en centros de donación de órganos, clínicas para tratamiento de enfermedades de transmisión sexual y de uso de drogas, así como también en los departamentos de urgencias, unidades obstétricas, y en otros sitios en los cuales se requieren resultados para las pruebas de VIH con elevada sensibilidad y especificidad, pero sobre todo, con suma prontitud, dado el nivel de urgencia para la toma de decisiones que es mandatoria en tales centros $(21,22)$.

Así, nuestro sistema de microelisa conjuga en un soloestuche, la elevada sensibilidady especificidad delELISA o microelisa con las innegables ventajas delas pruebas denominadas rápidas (<30 minutos) (21). Es este el primer paso de un desarrollo tecnológico que debe ser continuo.

\section{Agradecimientos}

El autor agradece al Laboratorio Biotecnológico de la Universidad INCCA de Colombia, por las facilidades que le brindaron en sus instalaciones para llevar a cabo el presente trabajo, muy especialmente al doctor Javier Vinasco y a la doctora Marcela Mendoza.

\section{Referencias}

1. Gallo R, Salahudin Sz, Popovic M, et al. Frequent Detection and isolation of cytopathic retroviruses (HTLV - III) from patients with AIDS and at risk of AIDS. Science $1984 ; 224: 500$.

2. Barre-Sinoussi F, Chermann JC, Rey F, et al. Isolation of $\mathrm{T}$. lymphotropic retrovirus from a patient at risk of adquired Immune deficiency syndrome (AIDS). Science 1983; 220:868.

3. Chang TW, Kato I, McKinney S, et al. Detection of antibodies to human T-cell lymphotropic virus III (HTLVIII) with an immunoassay employing a recombinant Escherichia coli derived viral antigenic peptide. Biotechnology 1985; 3:905.

4. Groopman JE, Chen FW, Hope JA, et al. Serological characterization of HTLV-III infection in AIDS and related disorders. J Infect Dis 1986; 153:736.

5. Davis GR, Blumeyer K, DiMichele LJ, et al. Detection of human immunodeficiency virus type 1 in AIDS patients using amplification-mediated hybridization analyses: reproducibility and quantitative limitations. $J$ Infect Dis 1990; 162:13.

6. Reesink HW, Lelie PN, Huisman HG, et al. Evaluation of six enzyme immoassays for antibody against human immunodeficiency virus. Lancet 1986; 2:483.

7. Popovic M, Sarngadharan MG, Reed E, et al. Detection, isolation and continous production of cytopathic retroviruses (HTLV-III) from patients with AIDS and pre-AIDS. Science $1984 ; 224: 497$.

8. Wang JJ, Steel S, Wisniewolski R, Wang CY. Detection of antibodies to human $\mathrm{T}$ - lymphotropic virus type III by 
using a synthetic peptide of 21 amino acid residues corresponding by a highly antigenic segment of gp41 envelope protein. Proc Natl Acad Sci USA 1986; 83:6159.

9. Gnann JW, McCormik JB, Mitchel S, et al. Synthetic peptide immunoassay distinguishes HIV type 1 and HIV type 2 infections. Science 1987; 237:1.346.

10. Gnann JW, Schwimmbeck PL, Nelson JA, et al. Diagnosis of AIDS by using a 12 -amino acid peptide repiesenting an immunodominant epitope of the human immunodeficiency virus. J Infect Dis 1987; 156:261.

11. Thorn R,Beltz GA, Hung Ch, etal.Enzyme immunoassay using a novel recombinant polypetide to detect human immunodeficiency virus env antibody. $\mathrm{J}$ Clin Microbiol 1987; 25:1.207.

12. Kennedy RC, Henker RD, Pauletti D, et al. Antiserum to a synthetic peptide recognizes the HTLV-III envelope glycoprotein. Science 1986; 231:1.556.

13. Wain - Hobson S, Sonigo P, Danos O, et al. Nucleotide sequence of the AIDS virus, LAV. Cell 1985; 40:9.

14. Ratner L, Haseltine W, Patarca R, et al. Complete nucleotide sequence of the AIDS virus, HTLV-III. Nature 1985; 313:277.

15. Merrifield RB. Solid phase peptide synthesis. Advances Enzymol 1969; 32:221.

16. Starcich BR, Hahn BH, Shaw G, et al. Identification and characterization of conserved and variable regions in the envelope gene of HTLV-III/LAV. The retrovirus of AIDS. Cell 1986; 45:637.

17. Engvall E, Perlman P. The enzyme linked immunosorbent assay (ELISA) III. Quantitation of specific antibodies by enzyme labelled anti-immunoglobulin in antigen-coated tubes. J Immunol 1972; 160:129.

18. Burgos JD, Mendoza M. Reactivity variation with respect to the incubation times in enzymatic immunoassays. En preparación.

19. De Cock KM, Parter A, Kovadio J, et al. Rapid and specific diagnosis of HIV1 and HIV2 infections: an evaluation of testing strategies. AIDS 1990; 4:875.

20. Novoa LI, Machado J, Benítez J, et al. Desarrollo de un ensayo de segunda generación para la detección de anticuerpos contra el $\mathrm{VIH}-1$. Biotecnología Aplicada 1992; 9:140.

21. Heyward WL, Curran JW. Rapid screening tests for HIV infection. JAMA 1988; 260:542.

22. Carlson JR, Mertens SC, Yen JL, et al. Rapid, Easy and economical screening test for antibodies to human immunodeficiency virus. Lancet 1987; 1:361.

23. Hodges RS, Senchuk PD, Taneja AK, et al. Protein design using model synthetic peptides. Research 1988; $1: 19$. 